\title{
Enhancement of Heat Transfer in Solar Air Heater Roughened with Circular V Rib Having Gap
}

\author{
Kulbir Singh \\ Department of Mechanical Engineering \\ Lala Lajpat Rai Institute of Engineering and Technology, Moga Punjab, India. \\ Sunaina \\ Department of Applied Sciences \\ CGC Technical Campus, Jhanjeri,Mohali,Punjab,India. \\ Gurpreet Singh \\ Department of Mechanical Engineering \\ Lala Lajpat Rai Institute of Engineering and Technology, Moga Punjab, India.
}

\begin{abstract}
This paper presents the results of heat transfer enhancement of a solar air heater with v-down rib having gap roughness on the air flow side of the absorber plate. Ribs were attached on absorber plate, having angle of attack $\left(\alpha=60^{\circ}\right)$. The ratio of rib height to hydraulic diameter (e/D) was $0.04770 \mathrm{~mm}$, while the range of rib pitch-to-height ratio was $(\mathrm{P} / \mathrm{e}=4,8$ and $16 \mathrm{~mm})$. Experiments were carried out using air as the convective fluid, with the Reynolds number range $(\operatorname{Re}=1825$ - 7759). The heat transfer of this roughened duct has been compared with those of the smooth duct under similar flow condition. The thermal efficiency by providing gap of $8 \mathrm{~mm}$ in $\mathrm{V}$ - shaped rib roughness on absorber plate is approximately $20-21 \%$ more as compared to smooth plate.
\end{abstract}

Keywords - Solar air heaters, angle of attack, heat transfer, Reynolds number, thermal efficiency

\section{INTRODUCTION}

Solar air heaters is the major component of solar energy utilization system which absorbs the incoming solar radiation, converting it into thermal energy at the absorbing surface, and transferring the energy to a fluid flowing through the collector. The thermal efficiency of solar air heaters has been found to be generally less because of their inherently low heat transfer capability between the absorber plate and air flowing in the duct. In order to make the solar air heaters economically viable, their thermal efficiency needs to be improved by enhancing the heat transfer coefficient. In order to attain higher heat transfer coefficient, the laminar sub-layer formed in the vicinity of the absorber plate must be broken and the flow at the heat-transferring surface is made turbulent by introducing artificial roughness on the surface.

The main applications of solar air heaters are space heating, drying of agricultural products and paint spraying operations. Several methods, including the use of fins, artificial roughness and packed beds in the ducts, have been proposed for the enhancement of thermal performance. Use of artificial roughness in the form of repeated ribs of various shapes and orientations has been found to be a convenient method to investigate the performance of such systems.

H.C. Hottel and B.B. Woertz [1] studied the performance of flat plate solar heat collector. It has been found the top loss coefficient is evaluated by considering losses due to convection and radiation from the absorber plate in the upward direction and requires iterations. They uncoupled these equations, separated convection and radiation terms and assumed equal resistance between sets of parallel plates. K. Pottler et al. [2] studied the optimized finned absorber geometries for solar air heating collectors. They observed that fin causes increase in surface area for heat 
transfer to air and hence results in increase in useful heat gain by the air with simultaneous increase in pressure drop. K.B. Muluwork et al. [3] experimentally studied the heat transfer and friction factor in solar air heaters roughened with staggered discrete ribs. AME. Momin et al. [4] studied the heat transfer and friction in solar air heater with vshaped rib roughness on absorber plate. It was found that for V-up rib, the maximum enhancement in Nusselt number and friction factor occurred for angle of attack of $60^{\circ}$, followed by $45^{\circ}, 90^{\circ}$ and $30^{\circ}$. The maximum enhancement in Nusselt number and friction factor was 2.30 and 2.83 times respectively as compared to smooth duct for angle of attack of $60^{\circ}$. V.S. Hans et al. [5] found that the heat transfer and friction factor correlations for a solar air heater duct roughened artificially with multiple V-ribs. They concluded that the maximum enhancement in Nusselt number and friction factor has been found corresponding to angle of attack $(\alpha)$ value of $60^{\circ}$ and relative roughness pitch $(\mathrm{P} / \mathrm{e})$ of 8 .

Sukhmeet Singh et al. [6] investigated the thermo-hydraulic performance due to flow-attack-angle in V-down rib with gap in the rectangular duct of solar air heater. They observed that V-shaped rib with small gap shows better results. A. Kumar et al. [7] studied the development of correlation of Nusselt number and friction factor for solar air heater with roughened duct having multiple v-shaped with gap rib as artificial roughness. Gurpreet Singh and G. S. Sidhu [8] investigated the enhancement of heat transfer of solar air heater roughened with circular transverse RIB. It has been found that thermal efficiency of roughened duct is 5\% - 9\% more as compared to the smooth duct. Ashok Singh Yadav et al. [9] invstigated CFD based analysis of solar air heater having V-Shaped perforated blocks on absorber plate. J.L. Bhagoria et al. [10] investigated on CFD simulation for thermo-hydraulic performance V-shaped discrete ribs on the absorber plate of solar air heater. It has been found the thermal efficiency enhancement of heat transfer because of selected roughness is found to be $16-24 \%$. The results predict a significant enhancement of heat transfer as compared to that of for a smooth surface with different pitch and various range of Reynolds number.

In the present work, experimental investigation on the performance of solar air heater ducts, having the absorber plate with artificial roughness in the form of V-shape rib, provided with gap, has been carried out in actual atmospheric conditions. The flow Reynolds number has been varied between 1825 and 7759 , relative roughness height 0.0477 , relative roughness pitch 4,8 and $16 \mathrm{~mm}$ and angle of attack $60^{\circ}$.

\section{EXPERIMENTAL APPARATUS}

An experimental test setup has fabricated to conduct the experimental investigations of solar air heater having Vshape rib with gap of 4, 8 and $16 \mathrm{~mm}$. An outdoor setup has been placed under direct sunlight for examine effect of $\mathrm{V}$-shape rib roughness. The experimental set-up is shown in Fig.1. The flow system consists of an entry section, a test section, an exit section, a flow meter and a centrifugal blower. The duct is of size length, width and depth of $2200 \mathrm{~mm} \times 520 \mathrm{~mm} \times 25 \mathrm{~mm}$ (dimension of inner cross-section) and is constructed from wooden panels. The absorber plate is $1 \mathrm{~mm}$ thick galvanized iron (GI) sheet. The length of GI sheet is $1900 \mathrm{~mm}$. The two sides of duct are covered with wood having $45 \mathrm{~mm}$ thickness and bottom is insulated with $76 \mathrm{~mm}$ thick glass wool.

The side of G.I sheet (absorber plate) is painted with dull black color to increases the absorber efficiency. A $4 \mathrm{~mm}$ thick glass cover is fixed above the absorber plate and wooden box is fitted like duct to place thermometer at the outlet of duct. Before starting the experiment, all instruments and components of experimental set-up have been checked for proper operation. After switching on blower, joints of set-up have been checked for air leakage. Blower sucks the air through duct and pipe and control valve regulate and change the flow of air. The detailed constructional features of individual components are as under; the cross-section of the rectangular duct is shown in figure 1. Figure 2 shows the direct photograph of the experimental setup. 

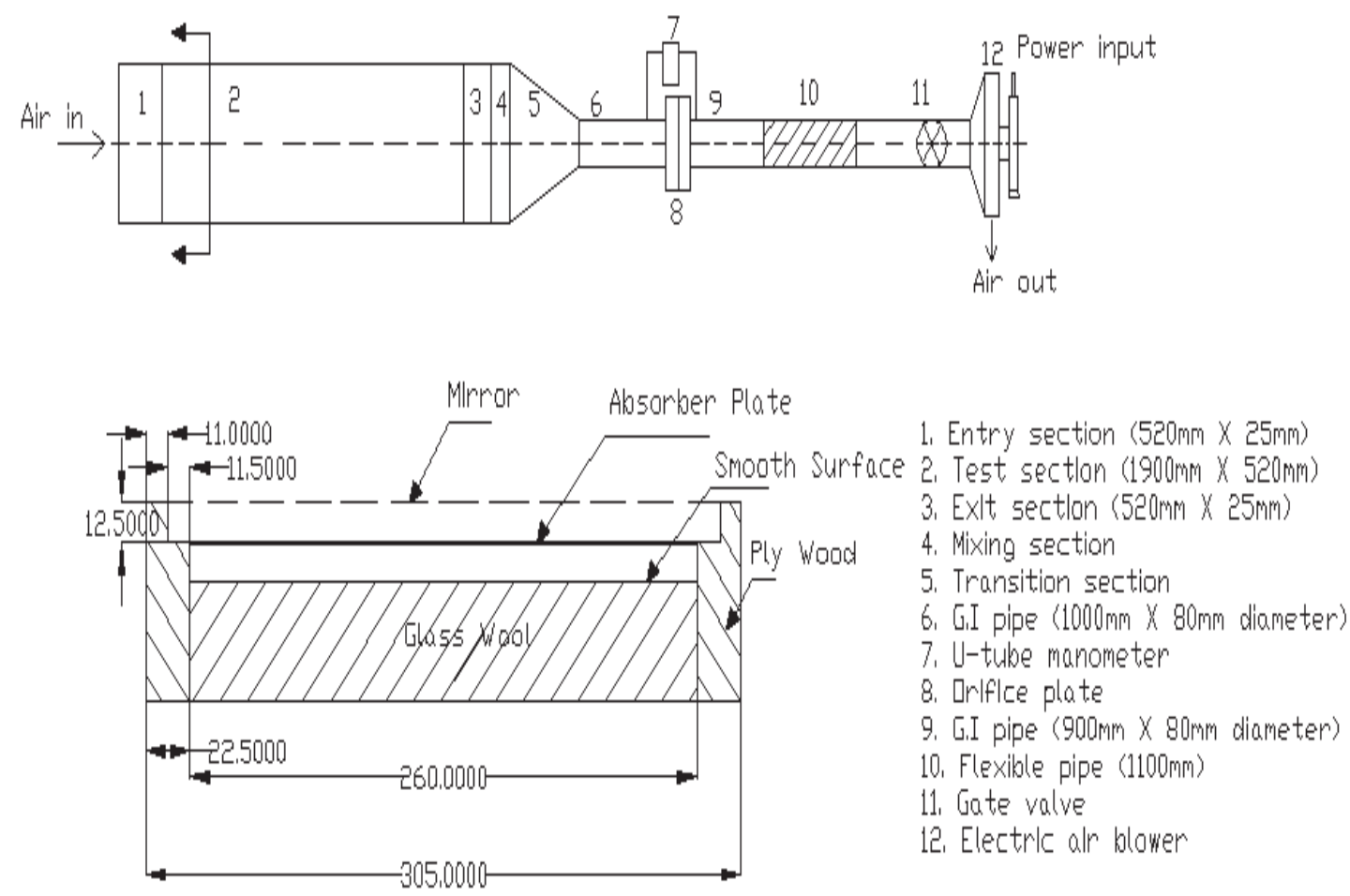

Scale liz

Figure 1 Schematic diagram of experimental setup.

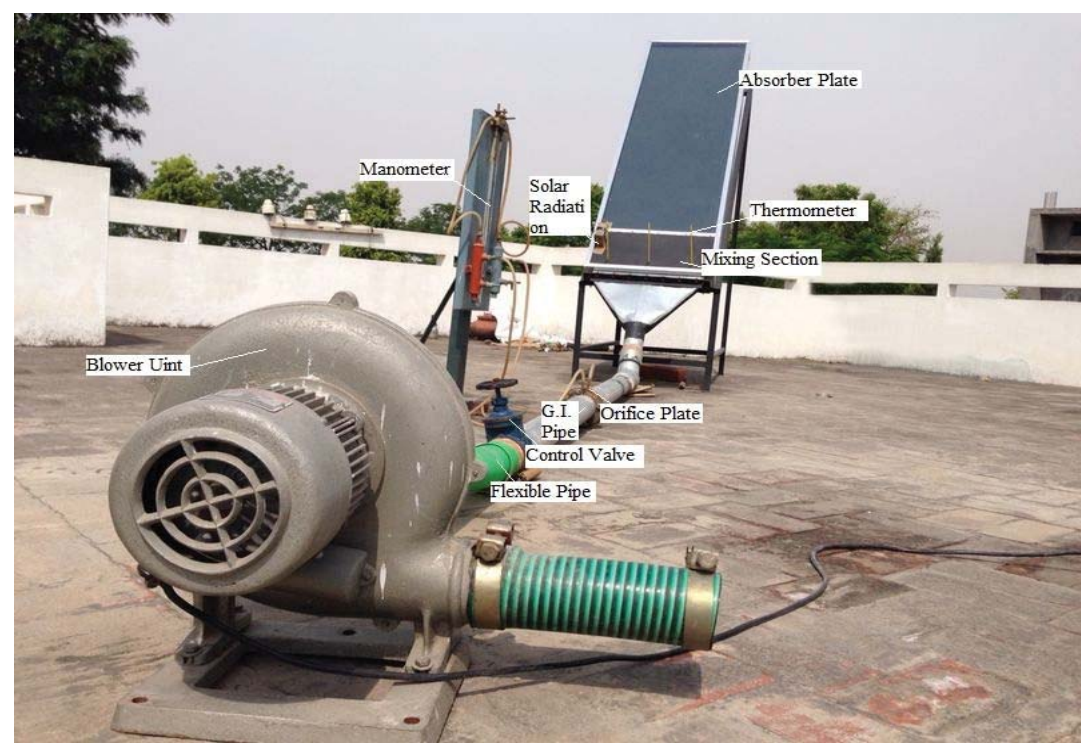

Figure 2 Direct photograph of the experimental setup. 
Figure 3 shows the arrangement of V-shape down ribs on absorber plate with gap of 4, 8 and $16 \mathrm{~mm}$. Aluminum wires were used to create artificial roughness on the underside of the absorber plate. Similarly, the value of the angle of attack is chosen as 60 o,to achieve maximum enhancement of heat transfer. The arrangements of ribs on the absorber plate are shown in figure 3 to investigate the effects of rib gap on thermal efficiency.
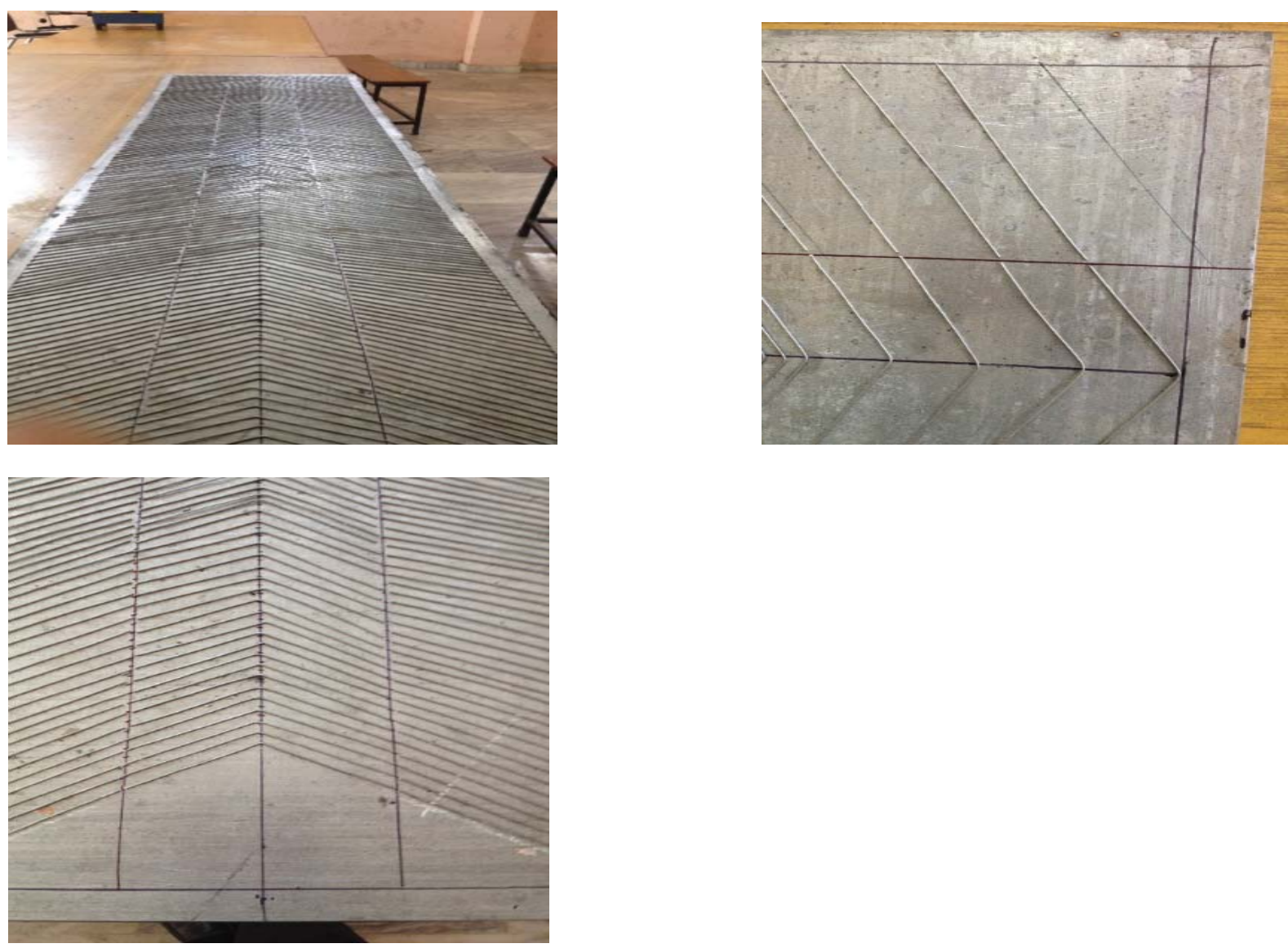

Figure 3 V-Down rib absorber plate having gap of 4, 8 and $16 \mathrm{~mm}$.

\section{EXPERIMENTAL PROCEDURE}

During the test runs, all data have been recorded and checked. For each experimental run, the following observations were recorded:

1. Inlet (ambient) temperature of air

2. Outlet temperature of air

3. Solar radiation intensity

4. Pressure drop across the test section

Table no. 1 shows the parameter and their range used to investigate the thermal efficiency of roughened solar air heater. 
Table No. 1 Roughness Parameters

\begin{tabular}{|c|c|c|}
\hline Sr. & Parameter & Range \\
\hline 1. & Reynolds number (Re) & $1825-7759$ \\
\hline 2. & $\begin{array}{l}\text { Relative roughness pitch } \\
(\mathrm{P} / \mathrm{e})\end{array}$ & 4,8 and $16 \mathrm{~mm}$ \\
\hline 3. & Air flow rate & $\begin{array}{l}0.008 \mathrm{~kg} / \text { ges }-\mathrm{m}^{2}- \\
0.036 \mathrm{~kg} / \text { ggs }-\mathrm{m}^{2}\end{array}$ \\
\hline 4. & Angle of attack $(\alpha)$ & $60^{\circ}$ \\
\hline 5. & $\begin{array}{l}\text { Relative roughness height } \\
\text { (e/Dh) }\end{array}$ & 0.04770 \\
\hline 6. & $\begin{array}{l}\text { Relative gap position } \\
\text { (d/w) }\end{array}$ & 0.65 \\
\hline 7. & Relative gap width (g/e) & 1 \\
\hline
\end{tabular}

\section{DATA REDUCTION}

(a) Mean temperature of air at inlet and outlet of the duct.

The mean temperature of air outlet (To) by weighted average method and the temperature at inlet of duct is direct measured as ambient temperature $\left(\mathrm{T}_{\mathrm{a}}\right)$.

$\mathrm{T}_{\mathrm{a}}=$ ambient temperature $\left({ }^{\circ} \mathrm{C}\right)$

$T_{\sigma}=\frac{T_{1}+T_{p}+T_{S}}{g}$ is called mean temperature at outlet of the duct.

(B) MASS FLOW RATE OF AIR

Mass flow rate of air has been determined from using the following relationship:

$m=Q \times \rho$

Where, $\mathrm{m}$ is mass flow rate of air and $\mathrm{p}$ is the air density and $\mathrm{Q}$ is discharge. 
Mass flow rate of air was taken according to area of the absorber plate and the ranges were between 0.008

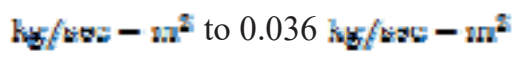

$\mathrm{Q}=\mathrm{C}_{\mathrm{i}} \frac{A_{1} \times A_{2}}{\sqrt{A_{1}^{2}-A_{2}^{2}}} \sqrt{2 g h a}$

Where, $\mathrm{Q}$ is a coefficient of discharge.

$A_{1}$, area of plate, $\mathrm{m}^{2}$

$\mathrm{A}_{2}$, area of orifice, $\mathrm{m}^{2}$

$\mathrm{C}_{\mathrm{d}}$, coefficient of discharge assuming 0.62

$h_{\mathrm{a}}=h_{\mathrm{m}}\left(\frac{\rho_{\mathrm{m}}}{\rho_{\mathrm{a}}}-1\right)$

Where, $h_{m}$, manometric height of fluid $\mathbf{p}_{\mathrm{m}}$, density of manometric fluid (water $1000 \mathrm{~kg}_{\mathbf{g}} / \mathrm{m}^{\mathbf{q}}$ ) $\mathbf{p}_{\mathrm{a}}$, density of air $\ln \mathrm{mi}$.

(c) Velocity of air through duct

The velocity of air is obtained from the calculated values of mass flow rate of air and flow area as,

$\mathrm{m}=$ Mass flow rate, $\mathrm{kg} / \mathrm{sec}$

$$
V=\frac{m}{P_{\mathrm{gar}} W H}
$$

$\mathbf{P}_{\text {air }}=$ Density of air in $\mathrm{kg} / \mathrm{m}^{\mathrm{\gamma}}$

$\mathrm{H}=$ Height of the duct in $\mathrm{m}$

$\mathrm{W}=$ Width of the duct, $\mathrm{m}$

(d) Equivalent hydraulic diameter

The hydraulic diameter of the rectangular section of the duct is determined from the relationship as given below:

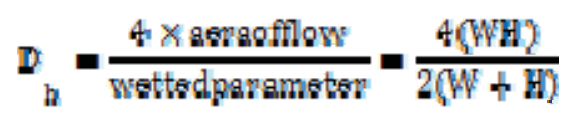

(e) Reynolds number (Re)

The Reynolds number of air flow in the duct is calculated from the following relationship:

$R=\frac{V D_{h}}{V}$

(f) Useful gain

$$
\mathrm{a}=\mathrm{mc}_{\mathrm{p}} \Delta \mathrm{T}
$$

\section{(g) Thermal efficiency $\left(\eta t_{h}\right)$ \\ westul galn (a) \\ - Rachatlen ba Avea of absobsep plats}

\section{RESULT AND DISCUSSION}

The heat transfer characteristics of rectangular duct roughened with $60^{\circ}$ inclined V-shaped ribs, computed on the basis of experimental data collected for various flow and roughness parameters. Figure 4 shows the effect of Reynolds number on thermal efficiency for fixed values of angle of attack $(\alpha)$, relative roughness height $\left(e / D_{h}\right)$ and 
different values of relative roughness pitch (p/e). Thermal efficiency of V-shaped roughened duct is higher than that of smooth duct. The value of heat transfer coefficient (h) increases with increasing the value of relative roughness pitch, it attains maximum value of relative roughness pitch $(\mathrm{p} / \mathrm{e}) 8 \mathrm{~mm}$, than it decreases with increasing relative roughness pitch. It is attributed due to flowing air strike with ribs and break laminar sub layer which creates local wall turbulence causes flow separation and reattachment between consecutive ribs which reduce the thermal resistance and increases the heat transfer. It also observed that thermal efficiency increasing with increases of Reynolds number for both smooth and roughened duct. The thermal efficiency was found maximum at relative roughness pitch $(\mathrm{p} / \mathrm{e}) 8 \mathrm{~mm}$ because of possibility of occurrence of reattachment point in this parameter. Literature [10], [12] and [13] also support this result because of maximum heat transfer occurs in the vicinity of reattachment point. The maximum experimental thermal efficiency of roughened solar air heater has been found to be approximately $20 \%-21 \%$ more as compared to smooth duct as shown in figure 4.

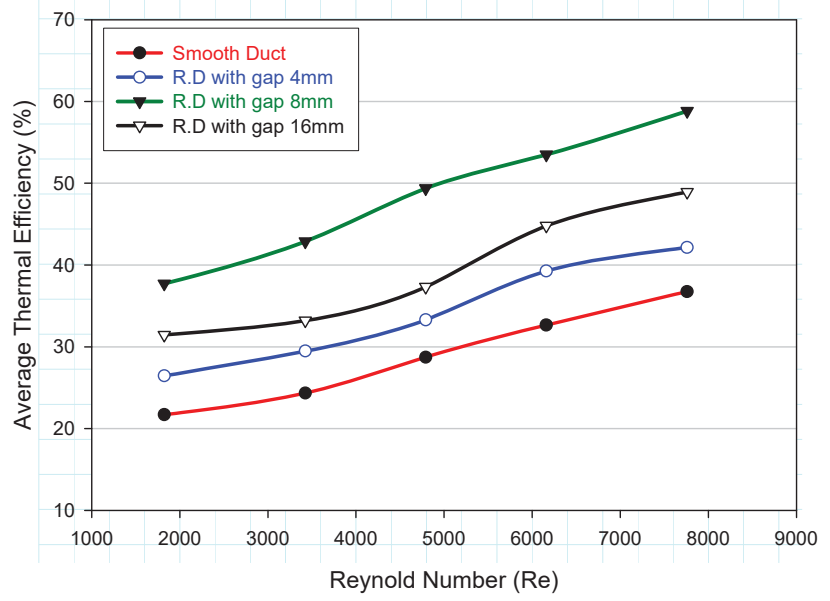

Figure 4 Variations of average thermal efficiency with respect to Reynolds number between smooth and three roughened ducts 4,8 and $16 \mathrm{~mm}$.

\section{CONCLUSION}

The following conclusions were made from the present study are:

1) The comparison between smooth and roughened surfaces at different air flow rates show that the average thermal efficiencies of roughened duct is approximately $20-21 \%$ more as compared to smooth duct.

2) It has been concluded that maximum heat transfer occurs at with gap of $8 \mathrm{~mm}$ rib roughness geometry.

\section{REFERENCES}

[1] H.C. Hottel, B.B. Woertz, "The performance of flat plate solar heat collectors", Trans. ASME, Vol. 64, pp.91-104, 1942.

[2] K. Pottler et al. "Optimized finned absorber geometries for solar air heating collectors", Solar Energy, Vol. 67, pp.35-52,1999.

[3] K.B. Muluwork et al. "Study of heat transfer and friction factor in solar air heaters roughened with staggered discrete ribs", Proceeding of 4th ISHMT-ASME and 15th National Conference on Heat and Mass Transfer, Pune, Jan.12-14, 2000.

[4] AME. Momin et al. "Heat transfer and friction in solar air heater with v-shaped rib roughness on absorber plate", International Journal of Heat and Mass Transfer, Vol. 45, pp.3383-3396, 2002.

[5] V.S. Hans et al. "Heat transfer and friction factor correlations for a solar air heater duct roughened artificially with multiple V-ribs", Solar Energy, Vol. 84, pp.898-911, 2010.

[6] Sukhmeet Singh et al. "Investigations on thermo-hydraulic performance due to flow-attack-angle in V-down rib with gap in the rectangular duct of solar air heater", Applied Energy, Vol. 97, pp.907-912, 2012.

[7] A. Kumar et al. "Development of correlation of Nusselt number and friction factor for solar air heater with roughened duct having multiple $\mathrm{v}$ - shaped with gap rib as artificial roughness", Renewable Energy, Vol. 58, pp.151-163, 2013.

[8] Gurpreet Singh, Dr. G. S. Sidhu "Enhancement of heat transfer of solar air heater roughened with circular transverse RIB" International Advanced Research Journal in Science, Engineering and Technology Vol. 1, Issue 4, December 2014.

[9] Ashok Singh Yadav et al. "CFD Based Analysis of Solar Air Heater Having V-Shaped Perforated Blocks on Absorber Plate" International Research Journal of Engineering and Technology (IRJET), Volume: 02 Issue: 02 May-2015.

[10] J.L. Bhagoria et al. "CFD Simulation for Thermo-Hydraulic Performance V-Shaped Discrete Ribs on the Absorber Plate of Solar Air Heater" World Academy of Science, Engineering and Technology International Journal of Energy and Power Engineering Vol: 3, No: 6, 2016. 